\title{
ФАБРИЧНО-ЗАВОДСКИЕ КОМИТЕТЫ, ИЛИ КООПЕРАТИВНЫЙ ПУТЬ В ОБЩЕСТВО БУДУЩЕГО - ШАНС, УПУЩЕННЫЙ РОССИЕЙ В 1917-1918 ГГ.
}

\author{
(c) 2021 Лебедев Константин Николаевич \\ доктор экономических наук, профессор, профессор Департамента экономической теории \\ Финансовый университет при Правительстве Российской Федерации, Россия, Москва \\ E-mail: KNLebedev@fa.ru \\ ORCID: https://orcid.org/0000-0002-4846-8097
}

В статье показано, что кооперативный путь перехода к обществу будущего является такой же реальностью, как и государственно-капиталистический путь, реализовывавшийся в нашей стране в 1930-е-1950-е гг. и обеспечивший опережающий рост экономики СССР по сравнению с экономикой мира. Именно кооперативный, причем, более эффективный, чем государственнокапиталистический, путь в лучшее общество реализовывался в нашей стране более чем год после победы Февральской революции 1917 года в виде рабочего контроля, или движения фабричнозаводских комитетов. Этот путь был заблокирован партией большевиков, для которых, стремившихся к бессрочной и безраздельной власти в стране, единственно приемлемым был государственнокапиталистический путь.

Ключевые слова: нефинансовая экономика, кооперативный путь, государственно-капиталистический путь, рабочий контроль, фабрично-заводские комитеты.

В наших (речь идет о группе авторов, разрабатывающих теорию нефинансовой экономики) работах было показано, что два представленных в марксистской теории пути перехода к обществу будущего - государственно-капиталистический (на основе госпредприятий, централизованно управляемых государством) и кооперативный (на основе предприятий, находящихся в собственности их трудовых коллективов, т.е. производственных кооперативов, добровольно объединяющихся в союзы разного уровня с целью планомерной организации производства и обмена в масштабах народного хозяйства) [5, с. 257] - соответствуют выводам теории нефинансовой экономики о том, что классическое (централизованно управляемое) госпредприятие и классический (учредители которого образуют его трудовой коллектив) производственный кооператив являются более эффективными формами крупного хозяйствования, чем классические (с полностью наемным персоналом, в том числе топ-менеджерами) акционерное общество (AО) и общество с ограниченной ответственностью (ООО) [4, с. 492-494]. При этом было показано, что с точки зрения теории нефинансовой экономики из двух нефинансовых (по способу наделения собственными средствами) форм организации предприятия - классического го- спредприятия и классического производственного кооператива - более эффективной формой хозяйствования является производственный кооператив (так как собственниками имущества кооператива выступают непосредственные исполнители производственных процессов, что придает им дополнительный стимул к высокопроизводительному труду и бережливому отношению к используемым средствам производства), из чего следует, что более приемлемым (прежде всего более быстрым) путем перехода к коммунизму выступает кооперативный путь [1, c. 481-482]. Также было показано, что «ранние» и «поздние» К. Маркс и Ф.Энгельс рассматривали в качестве пути перехода к коммунизму именно кооперативный путь, а государственнокапиталистический путь возник в их творчестве внезапно - он появился в «Манифесте коммунистической партии» (1848), который основоположники марксизма принялись писать сразу же после того, как Ф. Энгельс завершил «Принципы коммунизма», где значился кооперативный вариант перехода. Это было объяснено не экономическим выбором основоположников марксизма, а их политическим выбором. Дело в том, что в период написания Манифеста они фактически становились лидерами революционной пролетарской партии («Союза коммунистов»), 
рассчитывавшей захватить политическую власть в ряде стран, а как люди (прежде всего К. Маркс), желавшие не только лично нанести сокрушительный удар по «старому» миру (в виде победы руководимой ими пролетарской революции), но и лично поучаствовать в его полном уничтожении (в виде руководства ими остальными этапами социальной революции), отдали предпочтение менее эффективному государственнокапиталистическому пути, так как он в большей степени гарантирует эту возможность, поскольку партия (а значит и сами вожди) в этом случае обладает и экономической властью в стране. Кооперативный же путь, предполагающий самостоятельное формирование производственными кооперативами негосударственных органов народнохозяйственного управления, означает утрату партией экономической власти, что значительно ослабляет ее возможности (и возможности ее лидеров) навязывать свою волю стране и вообще не гарантирует удержания партии у власти [1, с. 484-486]. Заметим, что в данном случае речь идет именно о революционных (массовых) преобразованиях отношений собственности, так как огосударствление предприятий, как и развитие производственных кооперативов, может идти своим (эволюционным) чередом.

Было показано, что государственнокапиталистический путь развития нашей страны, осуществлявшийся в 1930-е-1950-е гг., обеспечил опережающий рост ее экономики по сравнению с экономиками развитых капиталистических стран [5, с. 254-255], что говорит о том, что государственно-капиталистический путь перехода к обществу будущего является реальностью. Цель настоящей статьи состоит в том, чтобы показать, что кооперативный путь перехода к обществу будущего - более эффективный, чем государственно-капиталистический - является не меньшей реальностью, поскольку именно он реализовывался в нашей стране в городской экономике более чем год после победы Февральской революции 1917 года. Он известен как рабочий контроль (на фабриках и заводах), или как деятельность фабрично-заводских комитетов (фабзавкомов, ФЗК), выступавших его органами.

Конечно же, кооперативный путь перехода к обществу будущего находил определенное подтверждение в реальной жизни и до российского рабочего контроля, без чего, на наш взгляд, К. Маркс не превратился бы в его сторонника, которым он предстает, кстати, уже в первом томе «Капитала» (написано в середине 1860-х гг.) а именно в главе двадцать четвертой, разумеется, если смотреть на первое издание данной книги (на немецком языке) [2], а не на ее варианты, «обработанные» Ф.Энгельсом. Из написанного К.Марксом в 1864 г. «Учредительного манифеста Международного Товарищества Рабочих...» (І Интернационала, существовавшего в 1864-1876 гг.) ясно, что таким подтверждением для него стало массовое движение рабочих, возникшее в результате революционных событий 1848 г., за создание кооперативных фабрик без всякой поддержки, доказавшее, как отмечает К.Маркс, что производство в крупных размерах и ведущееся в соответствии с требованиями современной науки возможно и в отсутствии класса хозяев, пользующихся наемным трудом, в связи с чем наемный труд должен уступить место ассоциированному труду, выполняемому добровольно, с готовностью и воодушевлением [8]. Важно отметить, что речь идет о рабочих ассоциациях, создаваемых, прежде всего, рабочими-единоличниками, формированию которых также препятствовала буржуазия. При этом признанию роли рабочих-единоличников в ее свержении и в последующем уничтожении частной собственности путем обобществления принадлежащих им средств труда неизбежно соответствует широкая трактовка революционного класса, т.е. включение в него не только пролетариата (наемных рабочих), но и всех трудящихся, в том числе трудового крестьянства, соответствующая, таким образом, духу «позднего», истинного марксизма.

Другим и очевидно даже более веским подтверждением реальности кооперативного пути для К.Маркса стала Парижская коммуна 1871 года, что ясно из работы «Гражданская война во Франции (Воззвание Генерального совета Международного Товарищества Рабочих)» (1871), где он описывает этот путь, запущенный Коммуной. Коммуна, как пишет К.Маркс, хотела экспроприировать экспроприаторов, превратив средства производства, землю и капитал, служащие орудиями порабощения и эксплуатации труда, в орудия свободного ассоциированного труда - но ведь это коммунизм. Если кооперативное производство должно вытеснить капиталистическую систему, если объединенные кооперативные товарищества организуют национальное производство по общему плану, взяв руководство им в свои руки и прекратив постоянную анархию 
и периодические конвульсии, неизбежные при капиталистическом производстве,- не будет ли это коммунизмом? [9, с. 346-347]. Очевидно, К. Маркса здесь вдохновила такая опробованная Коммуной массовая форма перехода к кооперативной форме хозяйствования, чем-то напоминающая российский рабочий контроль, как передача рабочим товариществам действующих производств, в частности им были переданы, как пишет К. Маркс, все закрытые мастерские и фабрики, владельцы которых бежали или приостановили работы [9, с. 351].

Однако, представляется, что рабочий контроль в России в 1917-1918 гг., ставший возможным благодаря Февральской революции 1917 года, является значительно более ярким подтверждением реальности кооперативного пути перехода к обществу будущего.

Рабочий контроль представлял собой именно кооперативную форму хозяйствования, поскольку состоял в непосредственном управлении предприятиями их трудовыми коллективами, рассматривавшими взятое в управление имущество предприятий как целиком заработанное трудом рабочих, что равносильно его рассмотрению как образовавшемуся за счет их имущественных взносов.

Рабочий контроль, начавший формироваться с начала марта 1917 г., уже в апреле-мае стал превращаться в полноценное непосредственное управление предприятиями со стороны их трудовых коллективов (через ФЗК), или в артельнообщинное самоуправление [16, с. 42-43], которое не могут позволить себе коллективы учредителей классических капиталистических предприятий (АО и ООО). Об этом говорят, прежде всего, мнения экспертов. Так, отмечается, что после перехода власти к Советам (в октябре 1917 г.) усилилась тенденция перерастания рабочего контроля в непосредственное рабочее управление [14]. Содержание инструкций и практического руководства по рабочему контролю, изданных Центральным советом фабзавкомов 6 января 1918 г., трактуется уже не как простое наблюдение ФЗК за действиями предпринимателей или их работа как «толкачей» по поиску сырья и топлива в помощь капиталистам для поддержки предприятия, а как деятельность ответственных лиц, выступающих фактическими руководителями всех дел предприятия (ФЗК могут приостанавливать действия хозяев и администрации, не разрешая без своего ведения или согласия при- нимать важные мероприятия, ведают продукцией, сырьем, топливом и рабочей силой, вместе с техническими служащими устанавливают план работ, вместе с администрацией рассматривают заказы и принимают решения об их выполнении, контролируют финансовые операции, осуществляют надзор за внутренним распорядком, расценками труда, в области санитарнотехнической и культурно-просветительской) [13].

Важно отметить, что непосредственное управление предприятием необязательно должно состоять в прямом замещении представляющими его рабочими должностей топ-менеджеров предприятия. Оно может состоять и в текущем контроле ими процессов принятия управленческих решений, осуществляемых топ-менеджерами, а также в проверке таковых, осуществленных (или неосуществленных) топ-менеджерами ранее. Заметим, что именно в таком контроле за деятельностью ключевых руководителей предприятия заключается деятельность эффективного генерального директора. При этом наряду с таким непосредственным управлением был распространен и случай прямого управления предприятиями рабочими. Д.О.Чураков приводит данные соответствующих обследований. Согласно одному из них, прямое рабочее управление имело место по стране в целом в 2,3\% случаев рабочего контроля, причем на крупных предприятиях - в 0,4\% случаев, а наибольшее число случаев прямого управления было в пищевой и горнодобывающей промышленности - 6,2 и 3,2\% случаев соответственно [16, с. 65]. Согласно другому, прямое управление имело место по стране в целом в 4,3\% случаев рабочего контроля, причем на Урале - в 13,1\% случаев, В Сибири и на Дальнем Востоке - в 12,3, на Украине - в 10,1, правда в Москве - всего только в 1,8\% случаев [16, с. 68]. Однако эти данные не дают истинной картины развития данного явления, так как относятся к периоду времени, когда государство уже вело активную борьбу с рабочим контролем (например данные первого обследования относятся к апрелю 1918 г.) и прежде всего с прямым рабочим управлением предприятиями (и прежде всего в столицах). За неимением прямых данных, о его значительном распространении можно судить по данным о масштабах захвата предприятий рабочими, очевидно, предполагающего создание рабочими собственного заводоуправления. Прямое рабочее управление связывает с захва- 
том предприятия рабочими Д. О. Чураков, также отмечающий масштабность данного явления (в сентябре 1917 г. в центральном промышленном районе по данным фабричных инспекторов, которые он считает заниженными -8 случаев захвата на 33 случая введения рабочего контроля, введение прямого рабочего управления на заводах Гужона, Бари, АМО, Дангауэра и Кайзера $[16$, c. 55]).

По некоторым данным, захват предприятий рабочими в стране носил массовый характер. Как вспоминает анархист Г.Максимов, за волной анархо-синдикалистской пропаганды, развязанной анархистами после Февральской революции 1917 года, последовала волна захватов предприятий и организации рабочего управления, наиболее громким случаем которой была экспроприация под управлением анархиста Жука Шлиссельбургских пороховых заводов и сельскохозяйственных угодий, причем данные события происходили все чаще, так что в преддверие Октябрьской революции 1917 года к ним стали относится как к чему-то само собой разумеющемуся [7]. Даже не сочувствующий анархистам источник отмечает, что в Петрограде агитация анархистов имела успех в Нарвском и Московском районах [14]. Заметим, что Нарвский район в 1917 г. был одним из четырех ведущих пролетарских районов столицы, а в работе (Лейберов, Шкаратан, 1961) он в числе таковых ставится на второе место (Выборгский, Нарвский, Василеостровский и Невский) [6, с. 54].

О значительных масштабах прямого рабочего управления может говорить и тот факт, что в начале марта 1917 года большинство рабочих Петрограда соглашалось вернуться к станкам в случае удовлетворения ряда требований, в число которых входило удаление неугодной администрации и управление заводами на выборных началах, реализация которых в определенных случаях может означать введение прямого рабочего управления предприятиями (при удалении неугодных топ-менеджеров и избрании в руководство рабочих) - другими требованиями были: арест и суд над царской семьей, конфискация земель, 8-часовой рабочий день, улучшение экономического положения рабочих. Также известно, что на заседании Петроградского Совета, проходившем в самом начале марта 1917 г., представители Сестрорецкого оружейного, Франко-Русского и Адмиралтейского заводов и Гребного порта требовали или объявляли о сме- не у себя администрации [14].

О непосредственном участии в управлении предприятиями их трудовых коллективов в целом, а не только членов или руководства ФЗК, говорят формы контроля за деятельностью ФЗК со стороны трудовых коллективов, например возможность немедленной замены «несправившихся» членов ФЗК, принятие решений на общих собраниях рабочих за подписями всех их участников [14].

Имущество предприятий рассматривалось рабочими как заработанное их трудом, что, как было сказано выше, равнозначно его рассмотрению как образованного за счет их учредительских взносов, на фоне низкого уровня заработной платы благодаря внедренному в сознание рабочих положению о том, что имущество предприятий (средства производства) есть недоплаченная рабочим заработная плата. Это положение внедрялось в их сознание десятилетиями как по анархистскому («собственность - это кража»), так и по марксистскому («экспроприация экспроприаторов», а по-русски - «грабь награбленное») каналам - теория неоплаченного труда, разработанная Р. Оуэном, была подхвачена как философом анархизма П.-Ж. Прудоном, так и К. Марксом [12]. Очевидно, что трудовые коллективы, перешедшие к рабочему контролю, были уверены, что право общей собственности на имущество предприятий будет закреплено за ними официально. Об этом говорит воззвание ФЗК Путиловского завода, в котором отмечалось, что приучаясь к самоуправлению, рабочие готовятся к тому времени, когда частная собственность на средства производства будет уничтожена и средства производства вместе со зданиями, возведенными рабочими, перейдут в руки рабочего класса [14].

Рабочий контроль представлял собой массовый переход действующих отечественных фабрик и заводов (и непромышленных предприятий) под непосредственное управление их трудовых коллективов по инициативе, как правило, самих трудовых коллективов. Д. О. Чураков приводит данные, согласно которым на 1 марта 1918 г. (через год после начала создания ФЗК в марте 1917 г.) в Московской области ФЗК существовали на 93\% из 326 обследованных предприятий, а по России в целом ФЗК были на $84,6 \%$ обследованных фабрик и заводов с числом работающих от 200 до 500 чел., 88,3\% - с числом работающих от 500 до 1000 чел., 92,3\% - с чис- 
лом работающих от 1000 до 5000 чел. [16, с. 121]. Заметим, что на предприятиях предпоследней категории до 1 октября 1917 г. возникли 85,5\%, а последней $-84,8 \%$ ФЗК [16, с. 121], что говорит о том, что на эту дату (через 7 месяцев с начала движения) рабочий контроль существовал уже на $75,5(88,3 * 85,5 / 100)$ и $78,3 \%(92,3 * 84,8 / 100)$ предприятий этих категорий соответственно. У нас нет данных о том, что подобный уровень обобществления предприятий достигался в результате революций 1848-1849 гг. или в период Парижской коммуны 1871 года.

Рабочий контроль применительно к значительно более высокому уровню развития науки и техники и централизации капитала, чем в середине XIX в., подтвердил возможность ведения крупного и современного производства на основе ассоциированного труда. Он существовал, прежде всего, на крупных (см. выше), а значит и на самых современных предприятиях, например на Путиловском заводе, коллектив которого насчитывал 26 тыс. чел. [11].

Подтверждением реальности кооперативного пути перехода к обществу будущего, естественно, является подтверждение более высокой эффективности производственного кооператива как формы хозяйствования по сравнению с капиталистическими АО и ООО. Понятно, что в случае, если рабочий контроль вводится на предприятии, уже разваленном саботажниками, то рост эффективности его деятельности при превращении в кооператив не говорит о преимуществах кооперативной формы хозяйствования. Однако до Октябрьской революции 1917 года рабочий контроль в основном сменял «нормальное» капиталистическое управление (при введении прямого рабочего управления или лишь при обнаружении первых попыток развалить производство) или носил форму помощи рабочих администрации и владельцам предприятия в ведении его дел (прежде всего в управлении процессом снабжения, проблемы которого, а не саботаж, в основном и приводили к остановке предприятий). О последнем лучше всего говорят обвинения большевиков в адрес ФЗК, обосновывавшие ликвидацию рабочего контроля, а именно в том, что ФЗК помогают капиталистам налаживать производство, чем вредят пролетарскому государству, прозвучавшие, например, на Первом Всероссийском съезде профсоюзов [16, c. 147-148]. При этом имеются данные в целом о росте эффективности деятельности частнока- питалистических предприятий, на которых был введен рабочий контроль (в помощь администрации) в это время. Так, по сведениям Петроградского общества фабрикантов и заводчиков, на 10-15 апреля 1917 г. из 34 владельцев механических заводов, приславших соответствующие сведения, 10 указали, что производительность труда повысилась или не изменилась, 15 отметили понижение производительности в основном по причине недостатка топлива и сырья, а 9 связали падение производительности с введением 8-часового рабочего дня, однако производительность сокращалась в меньшей мере, чем уменьшился рабочий день, например на «Новой бумагопрядильне» норма выработки сократилась на 15\%, тогда как рабочий день сократился на 24\% [14]. Обратим внимание на то, что данные с 10 заводов о росте или неизменном уровне производительности труда также относятся к случаю сокращения рабочего дня. Заметим, что у К. Маркса не было данных о более высокой эффективности производств, переданных кооперативам.

Важно отметить наличие данных о росте эффективности производства после введения рабочего контроля и на государственных предприятиях, управлявшихся до этого централизованно. Так, на Патронном заводе, откуда была удалена вся администрация, продуктивность упала только на 2\%, на Пороховом заводе, откуда также была изгнана почти вся администрация, уровень брака сократился с 30 до 15\%, на Орудийном заводе производительность увеличилась на $28 \%$, а на Оптическом - на 11 , Сестрорецкий завод стал выпускать в день вместо 450 винтовок и 4500 взрывателей 600 винтовок и 6000 взрывателей, Охтинский завод стал выпускать вместо 800 пудов пороха в сутки 900 пудов, при том, что уровень брака снизился с 35\% до 15 [14]. Также заметим, что падение производительности на Патронном заводе имело место в условиях введения 8-часового рабочего дня. Это подтверждает выводы теории нефинансовой экономики о том, что классический производственный кооператив является более эффективной формой хозяйствования, чем классическое госпредприятие, и о том, что кооперативный путь перехода к коммунизму является более приемлемым, чем государственно-капиталистический, а также, естественно, обоснованность взгляда «позднего» К. Маркса на лучший путь перехода к коммунизмy. 
Нами было показано, что более высокая эффективность нефинансовых форм организации предприятия (прежде всего, госпредприятия и производственного кооператива) по сравнению с финансовыми (АО и ООО) обусловлена свойственным первым высоким качеством управления предприятиями, выражающимся в отсутствии у него таких хронических болезней, как погоня за краткосрочной прибылью, предпочтение социального развития предприятия производственному, отсутствие тщательности в подборе методов управления, склонность к коррупции [4, с. 493-494]. Было показано, что еще основоположники марксизма выделили такие два симптома первой болезни управления $\mathrm{AO}$, чреватые кризисами и пролетарскими революциями, как снижение зарплаты рабочим до уровня прожиточного минимума и свободная конкуренция [4, с. 488-489], исключающая всякие попытки координировать рыночные действия с конкурентами к общему благу. У рабочего контроля таких симптомов не было. Аналогом первого симптома у рабочего контроля, очевидно, должно было быть сведение к минимуму доходов владельцев (собственников, учредителей) предприятий на вложенный капитал, чреватое, в данном случае, революцией уже капиталистов. Однако, как выясняется, ФЗК весьма щедро делились прибылью предприятий с их формальными хозяевами. Так, рабочие Ростокинской красильно-аппретурной фабрики, после того, как владельцы предприятия отказались выполнить их экономические требования, взяли управление предприятием на себя. Но при этом на общем собрании рабочих было установлено не извлекать особых выгод из самостоятельного управления фабрикой, весь доход после выплаты зарплаты рабочим и служащим по нормам и возмещения расходов по покупке средств производства передавать в собственность владельцев фабрики, исходя из того, что возможный в противном случае бойкот со стороны предпринимательских структур неизбежно вызвал бы падение выработки [16, с. 55].

ФЗК, начав появляться в марте 1917 г., уже с лета того же года стали объединяться в союзы разного уровня [16, с. 67]. Возникают и отраслевые союзы разного уровня, очевидно, с целью координации действий между предприятиямиконкурентами на основе учета интересов всех производителей отрасли (т.е. планомерной организации производства в рамках отдельных отраслей), например Объединенный комитет махорочных и спичечных фабрик в Ярославле, Совет трех текстильных фабрик Костромы в Костроме, Объединенный фабричный комитет предприятий гончарного производства Бронницкого уезда [16, с. 69]. Представитель ФЗК Москвы на Первой Всероссийской конференции фабзавкомов отметил, что капиталист, улучшая производство на своей фабрике, стремится подавить конкурентов, тогда как рабочие, улучшая производство на своей фабрике, стремятся распространить соответствующие улучшения возможно шире, что пролетариат должен стремиться к тому, чтобы продукт вырабатывался везде, где возможно, и в возможно большем количестве [16, с. 88]. Заметим, что после того, как АО в 1820-е гг. стало господствующей формой хозяйствования в Великобритании и США, ей понадобились десятилетия для того, чтобы дойти до отраслевых союзов. Создание всеми крупными производителями в отдельных отраслях «трестов» (фактически - картелей) и превращение целых отраслей в монополии (как это стало с английским производством щелочей, когда на базе 48 фабрик отрасли было создано одно акционерное общество с капиталом 120 млн. марок) Ф.Энгельс зафиксировал как новые явления капиталистического мира в работе «Развитие капитализма из утопии в науку», написанной им в 1880 г. [10, с. 221], т.е. более чем через 40 лет после вышеуказанного события. Рабочему же контролю в процессе его превращения в преобладающую форму хозяйствования (в городе) для формирования отраслевых ассоциаций предприятий понадобились считаные месяцы.

Заметим, что с лета 1917 г. возникают и территориальные союзы ФЗК разного уровня, например в Иваново-Вознесенске 22 июня 1917 г. на городской конференции ФЗК было сформировано Иваново-Вознесенское Центральное бюро ФЗК [16, с. 69], очевидно, с целью согласования действий между отдельными видами деятельности с учетом интересов всех отраслей (т.е. планомерной организации производства в рамках территорий).

Наконец, в результате объединительных тенденций, в августе 1917 г. (несмотря на противодействие большевиков) на Первой Всероссийской конференции ФЗК образуется Центральный совет ФЗК [3], который, очевидно, позиционируя себя как высший орган народнохозяйственного управления (в части рабочего контроля), правда, уже после Октябрьской революции 1917 г., пред- 
ставляет обширный план контроля над производством. Таким образом, на практике реализуется распространенная среди рабочих идея о том, что ФЗК, выступающие исполнительными органами рабочих коммун, соединяются в федеративную организацию, объединяющую всех рабочих и создающую необходимую систему управления. Как отмечали недовольные этим большевики, вместо «республики Советов» мы пришли к республике производственных кооперативов, в которой капиталистические фабрики должны быть изменены соответствующим процессом [7].

Теория нефинансовой экономики, объясняя вытеснение финансовых систем обеспечения (налоговых, кредитных, страховых, пенсионных и т.д.), в том числе капитальных (т.е. систем наделения предприятия собственными средствами при их создании и расширении, о которых идет речь в настоящей статье), их нефинансовыми альтернативами, обращает внимание не только на большую экономичность нефинансовых систем, но и на их большую доступность и безопасность, как для клиентов, так и для ресурсодателей. В данном случае тот же подход применяется в анализе конкурирующих нефинансовых капитальных систем, а именно классического госпредприятия и классического производственного кооператива, в том числе при их массовом применении. Покажем, что кооперативный путь перехода к коммунизму городской экономики был не только более экономичным (в силу большей производительности данной формы хозяйствования), но и более доступным и менее опасным.

Кооперативный путь был более доступным для рабочих, чем государственнокапиталистический, потому что в создавшихся после Февраля 1917 г. условиях решение о его использовании зависело почти исключительно от их желания. Для использования же государственно-капиталистического пути рабочие должны были ждать соответствующих решений государства, которое, в лице Временного правительства, очевидно, не стремилось к национализации частных городских предприятий сверх предела, диктуемого потребностями военного времени. Кооперативный путь также был менее опасным для рабочих путем перехода к обществу будущего, так как дееспособность соответствующей формы хозяйствования (чтобы она, например, не переродилась в
ООО) контролировалась снизу, т.е. коллективно (на уровне предприятий - их трудовыми коллективами, на уровне объединений ФЗК разного уровня - группами объединившихся ФЗК и их союзов), а дееспособность государственнокапиталистической формы хозяйствования - сверху. По этой причине централизовано управляемое госпредприятие оказалось весьма «хрупкой» формой хозяйствования - будучи сильно подверженной политическим влияниям. Как было нами показано, в СССР в результате борьбы за власть в стране между хозяйственными и чисто партийными деятелями, перевес в которой в пользу последних произошел после смерти И.В.Сталина в 1953 г. и прихода к власти Н.С.Хрущева, в экономике страны был запущен процесс постепенного перерождения классического госпредприятия в квазигосударственное предприятие с финансовой капитальной системой, известный под названием «Предоставление госпредприятиям хозяйственной самостоятельности» (более ясно - демонтаж административно-командной системы управления). В результате уже в 1960 -е гг. началось отставание советской экономики от мировой и капиталистической, что в итоге поставило «крест» на переходе СССР (и доверившихся огосударствленной экономике советских рабочих) к лучшему обществу, а затем и на самой стране [5, c. 254, 257-258].

Кооперативный путь был более доступным для российского государства после Февраля 1917 г., чем государственно-капиталистический, так как государству не нужно было тратить время и средства на его организацию (этим занимались сами предприятия, а точнее - их рабочие). Создание же «с нуля» адекватной системы централизованного управления экономикой (она существовала лишь в ВПК) требовало значительного времени и средств. Кооперативный путь был настолько доступен государству, что он тут же сам начал реализовываться. Кооперативный путь в форме рабочего контроля был более безопасным для государства путем перехода к обществу будущего, так как встречал меньшее сопротивление со стороны хозяев и владельцев частных предприятий, чем мог бы встретить государственно-капиталистический путь (а после Октября 1917 г. и встретил), несмотря на то, что есть свидетельства их крайнего недовольства введением рабочего контроля и активного противодействия его введению посредством разва- 
ла производств вплоть до локаутов, очевидно, особенно в случае захватов фабрик и заводов рабочими. Так, известно, что Моссовет и низовые советы были завалены жалобами фабрикантов и заводчиков на действия ФЗК [16, с. 38]. Но при оценке силы этого сопротивления следует учитывать «сговорчивость» ФЗК, обусловленную присущим рабочему контролю высоким качеством управления, в частности ориентацией на долгосрочные результаты, как в случае сохранения доходов владельцев предприятий (см. выше), что находило проявление также в приглашении администрации на заседания структур ФЗК (как на Тульском патронном заводе), согласии притормозить введение 8-часового рабочего дня [16, с. 37] и т.д. Также следует иметь в виду, что многие мероприятия ФЗК были в помощь администрации и хозяевам предприятий, например участие рабочих в управлении процессами снабжения и сбыта и контроле за соблюдением трудовой дисциплиной, а многие мероприятия, вызывающие сопротивление, были к долгосрочной выгоде администрации и хозяев (например, введение 8-часового рабочего дня), которую они затем могли и признать. Но главным, что, на наш взгляд, обеспечивало относительную безопасность кооперативного пути для государства, было то, что он, в отличие от государственнокапиталистического пути, не требовал мгновенной формальной экспроприации экспроприаторов. Сопротивление со стороны администрации и (бывших) хозяев частных предприятий их национализации чревато сильнейшим развалом производств и, что является еще более опасным для государства, попыткой капиталистической революции в виде гражданской войны. К последней и привели действия большевистского государства, которое с весны 1918 г. приступило ко второму, массовому этапу национализации, объектом которого стали не отдельные предприятия, а целые отрасли промышленности [17].

Кооперативный путь перехода к новому обществу в виде рабочего контроля, начавший реализовываться в нашей стране с мая 1917 г., в итоге был заблокирован большевиками, для которых единственно приемлемым был государственно-капиталистический путь. Еще до Октябрьской революции 1917 года большевики, формально поддерживая рабочий контроль с целью использования его возможностей для захвата власти (Красной гвардии и рабочей милиции, создававшихся ФЗК), пытались внедрить в сознание рабочих мысль от том, что ФЗК должны быть низовыми органами системы централизованного государственного народнохозяйственного управления, проводили резолюции о недопустимости захвата предприятий и о том, что ФЗК являются частью профсоюзной системы. 2 (15) декабря 1917 г. под предлогом того, что ФЗК слишком долго восстанавливают производство, создается Высший совет народного хозяйства (BCHX) как орган централизованного государственного управления народным хозяйством, а 3 марта 1918 г. выходит декрет ВСНХ, устанавливающий основы централизованного управления предприятиями, в соответствии с которым в каждой отрасли создается главк (центр), направляющий на каждое предприятие комиссара (представителя правительства) и административного и технического директоров [15]. Постепенно функции ФЗК ограничиваются. По мнению исследователей, переломным моментом в судьбе рабочего контроля стал Первый Всероссийский съезд Советов народного хозяйства (25 мая-4 июня 1918 г.), в соответствии с решением которого 2/3 фабрично-заводского управления предприятий назначаются областным Светом народного хозяйства [16, с. 160]. После начала массовой национализации предприятий, означающей окончательный отказ от кооперативного пути перехода к коммунизму (декрет от 28 июня 1918 г.), ФЗК завершают определенный для них большевиками путь превращения в низовые звенья госаппарата в виде низовых ячеек профсоюзов [16, с. 163].

Выбор большевиков (и их лидеров, прежде всего В.И.Ленина), как и ранее такой же выбор коммунистов в «Манифесте коммунистической партии» (1848), объясняется нами стремлением к бессрочной и безраздельной власти в стране соответствующих вождей после пролетарской революции, которую позволяет обеспечить госкапитализм. 


\section{Библиографический список}

1. Будович Ю.И., Будович М. С. Государственно-капиталистический и кооперативный пути перехода к коммунизму и партийная программа // Экономические науки. 2020. № 12 (193). C. 479-487. DOI: 10.14451/1.193.479.

2. Karl Marx. Das Kapital Erstausgabe 1867 / Archive.org. URL: https://archive.org/details/KarlMarxDasKapitalErsta usgabe1867/page/n755/mode/1up (дата обращения:11.01.2021).

3. Козловский С. Дети февраля / Центральная профсоюзная еженедельная газета Солидарность. Электронная версия. № 15. 18.04.2007. URL: https://www.solidarnost.org/thems/istoriya-profsoyuzov/istoriyaprofsoyuzov_3847.html (дата обращения: 13.01.2021).

4. Лебедев К. Н. Финансовые и нефинансовые капитальные системы и качество управления предприятиями // Экономические науки. 2020. № 12 (193). С. 488-497. DOI: 10.14451/1.193.488.

5. Лебедев К.Н. «Финансовый» характер собственности на средства производства в СССР и кризис советской экономики // Экономические науки. 2020. № 11 (192). С. 250-259. DOI: 10.14451/1.192.250.

6. Лейберов И.П., Шкаратан О.И. К вопросу о составе петроградских промышленных рабочих в 1917 году // Вопросы истории. 1961. № 1 Январь. С. 42-58.

7. Максимов Г. Синдикалисты в Российской революции / Международная ассоциация трудящихся. URL: https://aitrus.info/node/3396 (дата обращения: 15.09.2020).

8. Маркс К. Учредительный манифест международного товарищества рабочих, основанного 28 сентября 1864 г. на публичном собрании, состоявшемся в Сент-мартинс-холле, Лонг-эйкр, в Лондоне / K2X2.INFO. Библиотека. URL: http://www.k2x2.info/filosofija/sobranie_sochinenii_tom_16/p4.php (дата обращения: 03.01.2021).

9. Маркс К., Энгельс Ф. Сочинения. Издание второе. Том 17.- М.: Государственное издательство политической литературы, 1960. 842 (XXVIII) с.

10. Маркс К., Энгельс Ф. Сочинения. Издание второе. Том 19.- М.: Государственное издательство политической литературы, 1961. 671 (XXVI) с.

11. Ситуация на заводах и фабриках Петрограда в начале осени 1917 года / Санкт-Петербург. 05.09.2017. URL: https://topspb.tv/programs/stories/464966/ (дата обращения: 16.01.2021).

12. Собакин-Фисташков А. Собственность это кража / Проза.py. URL: https:/proza.ru/2020/05/05/2070 (дата обращения: 24.12.2020).

13. Фабзавкомы в России. Часть II. Фабзавкомы в период Октябрьской революции / Марксистско-ленинское рабочее движение. МЛРД «РАБОЧИЙ ПУТЬ». 30.12.2015. URL: https://work-way.com/blog/2015/12/30/ fabzavkomy-v-rossii-chast-ii-fabzavkomy-v-period-oktyabrskoj-revolyutsii/ (дата обращения: 06.10.2020).

14. Фабзавкомы - рабочая демократия в действии / ВРАГ КАПИТАЛА. URL: https://1917.com/History/ HRR/1082643581.html (дата обращения: 06.10.2020).

15. Фабрично-заводские комитеты: нелюбимое дитя революции / Альтернативы. 13.08.2007. URL: https:/ alternativy.ru/ru/content/fabrichno-zavodskie-komitety-nelyubimoe-ditya-revolyucii ～(дата обращения: 13.01.2021).

16. Чураков Д. О. Русская революция и рабочее самоуправление. 1917.- М.: «АИРО-ХХ», 1998. 204 с.

17. Экономическая политика советского государства (1917-1918 гг.) / і ИнфопедиЯ для углубленных знаний. URL: https: infopedia.su/4x58d7.html (дата обращения: 15.09.2020). 